Iğdır Üniversitesi Fen Bilimleri Enstitüsü Dergisi, 12(1): 152-163, 2022

Journal of the Institute of Science and Technology, 12(1): 152-163, 2022

Çevre Mühendisliği / Environmental Engineering

ISSN: 2146-0574, eISSN: 2536-4618

DOI: 10.21597/jist.1026987

Araştırma Makalesi / Research Article

Geliş tarihi / Received:22.11.2021

Kabul tarihi / Accepted:30.12.2021

Atıf İçin: Tırınk S, 2022. Hayvansal Atıkların Biyogaz Üretim Potansiyelinin Hesaplanması: Iğdır İli Örneği. Iğdır Üniversitesi Fen Bilimleri Enstitüsü Dergisi, 12(1): 152-163.

To Cite: Tırınk S, 2022. Calculation of Biogas Production Potential of Animal Wastes: Example of Iğdır Province. Journal of the Institute of Science and Technology, 12(1): 152-163.

\title{
Hayvansal Atıkların Biyogaz Üretim Potansiyelinin Hesaplanması: Iğdır İli Örneği
}

\section{Sevtap TIRINK ${ }^{1 *}$}

ÖZET: Tüm dünyada artan enerji talebini karşılamak ve çevre sorunlarını azaltmak amacıyla yenilenebilir enerji kaynaklarına olan talep her geçen gün artmaktadır. Bu kaynaklardan biri olan biyogaz enerjisi açısından ülkemiz zengin bir biyokütle potansiyeline sahiptir. Çalışmada, Iğdır ili ve ilçelerindeki hayvan işletmelerinden kaynaklanan atık miktarlarından biyogaz enerji potansiyellerinin belirlenmesi amacıyla yerel ölçüde sürdürülebilir çözümlerin geliştirilmesi amaçlanmıştır. 2020 y1lına ait Iğdır ili geneli için büyükbaş, küçükbaş ve kümes hayvan sayıları sırasıyla 157 426; 1279203 ve 265173 adettir. Hayvan gübresinden y1llık üretilebilecek biyogaz potansiyeli $43952304 \mathrm{~m}^{3}$, 1s1 enerji miktarı 1032879 GJ ve elektrik enerji miktarı $114716 \mathrm{MWh}$ olarak hesaplanmıştır. Iğdır ili için yıllık en yüksek elektrik üretim potansiyeline sahip olduğu Merkez ilçesinde 55367 MWh ve en düşük elektrik üretim potansiyeline sahip olduğu Karakoyunlu ilçesinde 15366 MWh elektrik enerjisi üretilebileceği hesaplanmıştır. Ayrıca Iğdır genelinde fosil yakıt yerine yenilenebilir enerji kaynaklarından biri olan biyogaz enerjisinin kullanılması ile y1llık 78465 ton karbondioksit emisyon salınımı engellenerek karbon tasarrufu sağlanabileceği hesaplanmıştır. Özellikle sera gazı emisyonlarının neden olduğu küresel isınmanın temiz enerji kaynakları kullanılarak azaltılması gerekmektedir. Çevre dostu olan bu tesislerin kurulması ile çevre problemlerine neden olan organik atıkların değerlendirilerek zararsız hale getirilmesine ve sera gazı emisyonlarının azaltılmasına katkı sağlayacaktır. Ayrıca bu tesislerden üretilecek olan enerji ile doğal kaynaklar korunacak ve ülke ekonomisine katkı sağlayarak sürdürülebilir kalkınmayı destekleyecektir.

Anahtar Kelimeler: Biyogaz, karbondioksit emisyonlarını azaltma, elektrik enerjisi, gübre, iklim değişikliği, arcgis

\section{Calculation of Biogas Production Potential of Animal Wastes: Example of Iğdır Province}

ABSTRACT: All over the world, the demand for renewable energy sources is increasing day by day both to meet the increasing energy demand and to reduce environmental problems. Our country has a rich biomass potential in terms of biogas energy, which is one of these resources. In study, it is aimed to develop locally sustainable solutions by determining the biogas energy potential from the waste amount resulting from animal enterprises in Iğdır province and its districts. The number of cattle, small ruminant and poultry for the province of Iğdır for 2020 is 157 426; 1279203 and 265 173, respectively. Biogas amount that can be produced annually from the manure of animals is calculated as $43952304 \mathrm{~m}^{3}$, the amount of heat energy as $1032879 \mathrm{GJ}$ and the amount of electrical energy as $114716 \mathrm{MWh}$. It has been determined that in the central district where it has the highest annual electricity generation potential for Iğdır province, $55367 \mathrm{MWh}$ and in the Karakoyunlu district where it has the lowest electricity generation potential, it has been determined that $15366 \mathrm{MWh}$ electricity can be produced. In addition, it has been calculated that by using biogas energy, which is one of the renewable energy sources, instead of fossil fuels throughout Iğdır, it is calculated that carbon savings can be achieved by preventing the emission of 78465 tons of carbon dioxide emissions annually. In particular, global warming caused by greenhouse gas emissions should be reduced by using clean energy sources. With the establishment of these environmentally friendly facilities, organic wastes that cause environmental problems will be evaluated and made harmless and greenhouse gas emissions will be reduced. In addition, the energy produced from these facilities will protect natural resources and support sustainable development by contributing to the national economy.

Keywords: Biogas, reduce carbon dioxide emissions, electric power, fertilizer, climate change, arcgis.

${ }^{1}$ Sevtap TIRINK (Orcid ID: 0000-0003-0123-0054), Iğdır Üniversitesi, Sağlık Hizmetleri Meslek Yüksekokulu, Çevre Sağlığı Programı, Iğdır, Türkiye

*Sorumlu Yazar/Corresponding Author: Sevtap TIRINK, e-mail: sevtaptirink@gmail.com 


\section{GíRíş}

Dünya nüfusunun zamanla hızlı bir şekilde artması, sanayileşmenin yeni boyutlar kazanması ve insanların yaşama standardını yükseltme istekleri, enerjiye olan gereksinimi arttırmıştır. Tüm dünyada olduğu gibi ülkemizde de enerjiye olan talep artış göstermektedir (Taşova, 2019; Taşova ve Yazarel, 2019). Bu artan enerji taleplerini karşılamak için ağırlıklı olarak kömür, petrol, doğalgaz gibi fosil kaynaklar kullanılmaktadır. Ancak bu kaynakların yenilenme hızlarının düşük ve miktar olarak talebi karşılamada yetersiz olmaları nedeniyle hızla tüketilmeleri söz konusudur. Ayrıca bu kaynakların fazla kullanımı özellikle hava kirliliğini oluşturması, ozon tabakasındaki incelmeyi arttırması, küresel ısınmayı hızlandırması ve asit yağmurlarının oluşması gibi çevresel problemlere neden olmaktadır. Günümüzde birçok araştırmacı bu kaynakların daha verimli kullanılması için yeni teknolojiler ve buluşlar geliştirmeye çalışırken, diğer taraftan da çevreyle dost, kaynakları sınırsız sayılabilecek olan yenilenebilir enerjinin kullanılması ve değerlendirilmesi konusunda çalışmalar yapmaktadır (Sözer ve ark., 2016).

Yenilenebilir enerji kaynakları (güneş enerjisi, jeotermal, hidroenerji, rüzgâr enerjisi ve biyokütle gibi) ile çevre dostu üretim sağlanabilmektedir (Argun ve ark., 2016). Bu kaynaklar karbondioksit $\left(\mathrm{CO}_{2}\right)$ emisyonlarının azalmasına katkı sağlayarak çevrenin korunmasına yardımcı olmaktadır. Ayrıca yerli ve kısa sürede yenilenebilir kaynaklar olmaları sebebiyle ülkenin enerjide dışa bağımlılığının azaltılmasını ve yeni istihdam alanlarının oluşmasını sağlamaktadır (Aktaş ve ark., 2015). Ülkemiz yenilenebilir enerji kaynakları bakımından zengin bir potansiyele sahip olduğundan kaynakların etkili bir şekilde kullanılması büyük önem taşımaktadır.

Yenilenebilir enerji kaynakları arasında yer alan biyokütle enerjisi, üretimdeki teşviklerden dolayı son yıllarda giderek uygulaması artmaktadır. Biyokütle enerji kaynaklarından elde edilen yakıtlardan biri olan biyogaz, organik esaslı atıkların anaerobik ortamda fermantasyonu sonucu ortaya çıkan gaz karışımıdır. Biyogaz, kokusuz, renksiz, havadan hafif, parlak mavi bir alevle yanan ve içeriğinde yaklaşık olarak \%55-75 metan $\left(\mathrm{CH}_{4}\right)$, \%24-44 karbondioksit $\left(\mathrm{CO}_{2}\right)$ ve çok az miktarlarda oksijen $\left(\mathrm{O}_{2}\right)$, hidrojen $\left(\mathrm{H}_{2}\right)$, azot $\left(\mathrm{N}_{2}\right)$, hidrojen sülfür $\left(\mathrm{H}_{2} \mathrm{~S}\right)$, amonyak $\left(\mathrm{NH}_{3}\right)$ ve karbon monoksit $(\mathrm{CO})$ bulunan gaz karışımıdır (Ardıç ve Taner, 2014; Aybek ve ark., 2015; Dağtekin ve ark., 2019). Biyogaz üretimi için yeterli organik madde, yeterli bakteri, uygun anaerobik ortam ve uygun ortam 1sıs1 olmas1 gereken önemli parametreleri oluşturmaktadır Biyogazın içeriği, fermantasyon mikroorganizmaları vasıtasıyla organik maddenin sindirim süresine, atığın türüne ve biyogaz üretiminin işletme şartlarına bağlı olarak değişiklik gösterirken, biyogazın enerji verimliliği ise $\mathrm{pH}$, sıcaklık ve iyi karıştırılma gibi parametrelerin uygun olmasına bağlı olarak değişiklik göstermektedir (Yetiş ve ark., 2019). Bu parametreler dikkate alınarak biyogaz sistemlerinin işletilmesi gerekmektedir.

Tüm dünyada ve Türkiye'de hayvansal atıkların uygun bir şekilde depolanmaması önemli çevre problemlerinin oluşmasına neden olabilmektedir. Bu atıkların sağlıksız depolama koşulları nedeniyle; kötü koku oluşumuna, zararlı canlıların çoğalmalarına, yüzeysel ve yeraltı su kaynaklarının kirlenmesine, yüzeysel su kaynaklarında ötrofikasyonun oluşmasına, yeraltı ve yüzeysel su kaynakları potansiyelinin azalmasına, türlerin yok olmasına, direkt tarım arazilerine verilmesiyle ürün kalitesinin azalmasına, sera gazı emisyonlarının artışına, küresel iklim değişikliğine neden olması gibi doğrudan ya da dolaylı olarak etkileri söz konusudur (Tırınk, 2021). Bu nedenle bu tür atıkların araziye uygulanıncaya kadar çevre problemleri yaratmayacak şekilde gerekli tedbirler alınarak muhafaza edilmesi gerekmektedir. Atıklara uygulanan havalandırma, biyogaz üretimi, kompost yapma ve kurutma gibi işlemler, bu tür atıkların çevreye daha az zarar vermesine neden olacaktır. Ayrıca atıklara uygulanan işlemler ile arıkların tarlada organik gübre olarak daha etkin kullanılmasıyla oluşturabileceği çevre problemlerinde önemli ölçüde azalma söz konusu olacaktır (Karaman, 2006). 
Biyogaz tesislerinin kurulması, hayvansal atıkların canlılara, su ve toprak kaynaklarına olan olumsuz etkileri azaltılarak ekonomik fayda sağlamaktadır (Boyacı ve ark., 2011). Nihayetinde, üretilen biyogaz sayesinde fosil yakıtlardan kaynaklanan çevre kirliliği azaltılarak sera gazı emisyon yayılımının önlenmesine ve enerji tasarrufu sağlayarak sürdürülebilir kalkınmanın desteklenmesine olanak sağlayacaktır (Yetiş ve ark., 2019).

Dünya geneline bakıldığında Türkiye, tarım ve hayvancılık alanında önemli bir konumdadır. Ülkemizdeki biyogaz enerji potansiyeli, tarımsal alanların, hayvan potansiyelinin, tarım ve hayvancilıkla ilgilenen nüfusun yüksek olmasından dolayı önemli bir enerji kaynağı potansiyelini oluşturmaktadır (Çağlayan ve Koçer, 2014; Seyhan ve ark., 2018; Dağtekin ve ark., 2019). Bu sebeplerden dolayı ülkemizdeki biyogaz enerji potansiyelinin değerlendirilmesi gerekmektedir.

$\mathrm{Bu}$ çalışmanın amacı, Iğdır ilinde bulunan hayvansal üretimden oluşan gübrelerin biyogaz enerji potansiyelini belirlemektir ve ilçelerdeki potansiyel dağılımını haritalamaktır. Ayrıca ülke politikaları ve ekonomik sürdürülebilirlik açısından biyogaz enerji potansiyeli ile elde edilebilecek güç miktarı belirlenmelidir. Çalışma kapsamında öncelikle 2020 yılı için Iğdır ilinde bulunan, büyükbaş, küçükbaş ve kanatlı hayvan sayıları tespit edilmiştir. Daha sonra bu hayvanların günlük oluşturdukları yaş gübre miktarları baz alınarak üretilen günlük ve yıllık yaş gübre miktarları hesaplanmıştır. Sonrasında hayvanların oluşturmuş olduğu gübrelerin biyogaz üretim potansiyelleri ve biyogazın 1sıl eşdeğerliğine göre üretilebilecek elektrik miktarları hesaplanarak belirlenmiştir. Üretilecek elektrik miktarına göre fosil yakıt kullanımından kaynaklanan emisyon miktarları göz önüne alınarak biyogaz üretimi sayesinde $\mathrm{CO}_{2}$ salınımında ne kadar azalma gösterdiği belirlenmiştir. Ayrıca bu hesaplamalar sonrasında bir Coğrafi Bilgi Sistemi (GIS) programı olan ArcGIS kullanılarak Iğdır ili ve ilçelerindeki potansiyel dağılımların haritalanması yapılmış ve haritalar sayesinde ilçelerdeki potansiyel dağılımın daha net görünmesi sağlanmıştır.

\section{MATERYAL VE METOT}

Bu çalışmada, Iğdır ili ve ilçelerindeki hayvansal atık kaynaklı biyogaz enerji potansiyellerinin belirlenmesi amacıyla hayvan sayısı verileri Türkiye İstatistik Kurumunun (TÜİK) 31.12 .2020 yılı verileri kullanılmıştır (TÜİK, 2020).

TÜİK verileri kullanılarak Iğdır ilinin ilçelerine göre hayvan sayısı dağılımı analiz edilmiştir. Hayvansal atıklardan toplanabilecek yaş atık miktarları hesaplanarak biyogaz üretim potansiyelinin hesaplamaları gerçekleştirilmiştir.

\section{Çalışma Alanı}

Iğdır ili, Türkiye'nin üç ülkeye (Nahçivan Özerk Cumhuriyeti, İran ve Ermenistan) sınırı olan Türkiye'nin Doğu Anadolu Bölgesi'nde yer alan bir ilidir. Bu ilin idare alanının doğu ve güneydoğusunda Nahçivan Özerk Cumhuriyeti ve İran, kuzeyinde Ermenistan, güneyinde Ağrı ili, batı ve kuzeybatısında ise Kars ili yer almaktadır. Yüzölçümü $3588 \mathrm{~km}^{2}$ 'lik bir alana sahip ve Iğdır Ovasının ortalama rakımı 800-900 m arasında değişmektedir. Iğdır ilinde Merkez ilçe ile 4 ilçe, 7 belde ve 162 köy bulunmaktadır. Bu ilçeler Iğdır (Merkez), Tuzluca, Aralık ve Karakoyunlu ilçeleridir (Şekil 1). Iğdır ili ve çevresi Türkiye ve Doğu Anadolu ölçüsünde kendine özgü iklim özelikleri ile yazları sıcak ve kurak, kışları ılıman bir iklime sahiptir (Aras ve Tekay, 2018). Ayrıca tarım ve hayvancılık bölgenin temel geçim kaynağını oluşturmaktadır. 


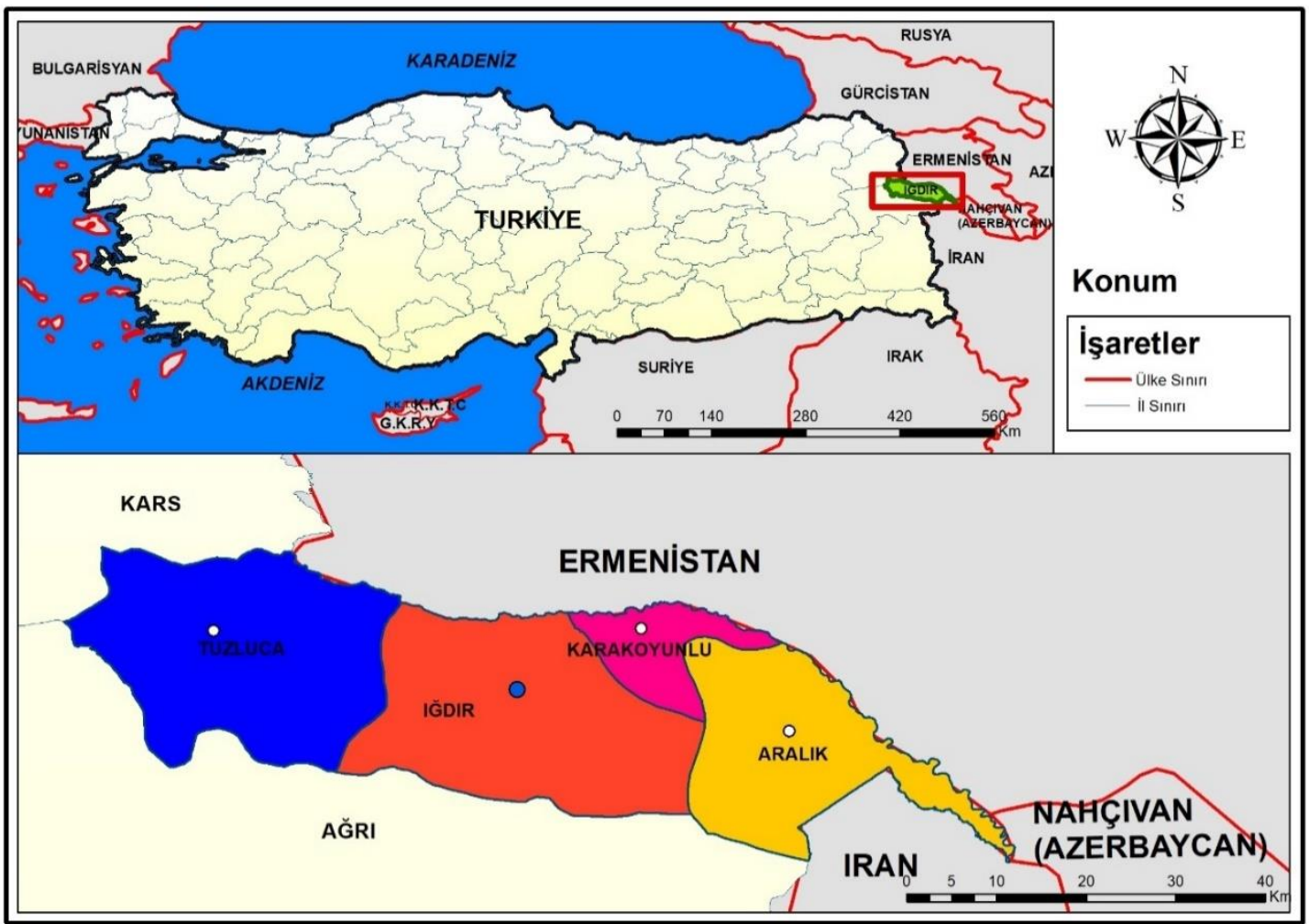

Şekil 1. Iğdır ili ve ilçeleri

\section{Biyogaz Potansiyelinin Belirlenmesi}

Gübre üretimi hayvanların beslenme yoğunluğuna ve besin türüne, su içme sıklığına göre çok değişken olabilmektedir (Kocabey, 2019). Iğdır ilinin biyogaz potansiyelinin hesaplanması için daha önce yapılan çalışmalar incelenmiştir. Biyogaz potansiyelini belirlemek için bu çalışmalardan yararlanarak bazı kabuller kullanılmıştır. Literatürde öngörülen değerler Çizelge 1'deki en küçük ve en büyük değer aralıkları baz alınarak belirlenmiştir (Omer ve Fadalla, 2003; Koçer ve ark., 2006; Avcıoğlu ve ark., 2013; Aktaş ve ark., 2015; Ilgar, 2016; Salihoğlu ve ark., 2019). Hesaplamalarda belirtilen aralıklardaki katsayı değerlerinin dışına çıkılmamıştır (Çizelge 2).

Çizelge 1. Hayvan cinslerine göre atık oluşum değer aralıkları

\begin{tabular}{lccc}
\multicolumn{1}{c}{ Kabul Parametreleri } & Büyükbaş Hayvan (BBH) & Küçükbaş Hayvan (KBH) & Kümes Hayvanı (KH) \\
\hline Canlı hayvan ağırlığı (kg) & $135-800$ & $30-75$ & $1.5-12$ \\
Yaş gübre oluşumu (\%) & $5-6$ & $4-5$ & $3-4$ \\
Yaş gübre üretim miktarı $\left(\mathrm{kg} \mathrm{gün}^{-1}\right)$ & $6-48$ & $1.2-3.75$ & $0.045-0.48$ \\
Kuru madde içeriği (\%) & $5-25$ & $30-36$ & $10-90$ \\
Uçucu kuru madde (\%) & $75-85$ & $20-81$ & $60-80$ \\
Kullanılabilirlik (\%) & $25-65$ & 13 & 99 \\
Biyogaz eşdeğerliği (m ${ }^{3}\left(\right.$ ton*UKM) $\left.^{-1}\right)$ & $200-350$ & $100-310$ & $310-650$ \\
\hline
\end{tabular}

Iğdır iline ait hayvansal atık kaynaklı biyogaz potansiyelinin hesabı için toplam yaş gübre miktarı (TYGM) aşağıdaki denklem ile hesaplanmıştır.

$$
T_{Y G M}=A_{C H} * Y_{C H A}
$$

Burada TYGM toplam yaş gübre miktarını (kg (gün*hayvan) $\left.{ }^{-1}\right), A_{C H}$ hayvan türüne göre canlı

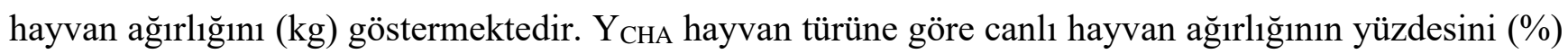
ifade etmektedir. Hayvanlarda yaş gübre üretim potansiyeli hayvanın kilosuna, cinsine, yaşına, cinsiyetine, beslenme türüne ve bulunduğu bölgenin iklim koşullarına göre değişiklik gösterebilmektedir. Ancak bu çalışmada Eşitlik 1 ve literatür değerleri (Çizelge 1) dikkate alınarak yaş gübre üretim miktarı $\mathrm{BBH}$ için $27 \mathrm{~kg}$ gün ${ }^{-1}, \mathrm{KBH}$ için $2.48 \mathrm{~kg}$ gün $^{-1}$ ve $\mathrm{KH}$ için $0.26 \mathrm{~kg}_{\text {gün}}{ }^{-1}$ olacağ kabul edilmiştir. 
Hayvanların merada oldukları süre boyunca hayvan atıkları toplanamayacağı ve tesisin sürekli işletilebilmesi için hammadde probleminin yaşanmaması amacıyla hesaplamada gübrenin tamamı kullanılmamaktadır. Bu sebepten dolayı toplam kullanılabilir yaş gübre miktarı ( $\mathrm{T}_{\mathrm{KYGM}}$ );

$T_{K Y G M}=T_{Y G M} * Y_{K G}$

şeklinde hesaplanmaktadır. Burada $\mathrm{T}_{\mathrm{KYGM}}$ toplam kullanılabilir yaş gübre miktarını (ton gün ${ }^{-1}$ ), $\mathrm{Y}_{\mathrm{KG}}$ hayvan türüne göre kullanılabilir gübre (\%) oranını ifade etmektedir. Bu değer BBH için \%65, KBH için \%13 ve $\mathrm{KH}$ için \%99 alınmıştır. Literatürde hayvan türüne bağlı biyogaz katsayısı kabulünde gübrenin kuru veya yaş olma durumuna göre iki farklı kabul kullanılmaktadır (Altıkat ve Çelik, 2012; Kaya ve Öztürk, 2012; Çağlayan ve Koçer, 2014; Ilgar, 2016; Baran ve ark., 2017; Doruk ve Bozdeveci, 2017; Şenol ve ark., 2017; Bayrak Işık ve Polat, 2018; Bulut ve Canbaz, 2019; Görgülü, 2019; Kocabey, 2019; Salihoğlu ve ark., 2019, Yağlı ve Yıldız, 2019; Yetiş ve ark., 2019; Ay ve Kaya, 2020). Yaş gübre hayvanın katı dışkısı, idrarı ve bulunduğu alanın yıkama sularını da içermektedir. Bu yüzden yaş gübrenin biyogaz elde edilebilecek kuru içeriğinin hesaplanması gerekmektedir. Dolayısıyla toplam kuru gübre miktarı $\left(\mathrm{T}_{\mathrm{KGM}}\right)$;

$T_{K G M}=T_{Y G M} * Y_{K M} * Y_{U K M}$

şeklinde hesaplanmaktadır. Burada $\mathrm{T}_{\mathrm{KGM}}$ toplam kuru gübre miktarını (ton*UKM gün ${ }^{-1}$ ), $\mathrm{Y}_{\mathrm{KM}}$ hayan türüne göre değişen hayvansal atıklardaki kuru madde (\%) oranını göstermektedir. Bu değer BBH için \%5-25 arasında, KBH için \%30 ve KH için \%10-90 arasında alınmaktadır. Y göre uçucu kuru madde (\%) oranıdır. Hayvan türüne bağlı oluşan 1 ton toplam kuru gübre miktarından BBH için 200-300 $\mathrm{m}^{3}$ (ton* $\mathrm{UKM}^{-1}$ arasında, $\mathrm{KBH}$ için 100-350 $\mathrm{m}^{3}$ (ton*UKM) ${ }^{-1}$ arasında ve KH için 310-650 $\mathrm{m}^{3}$ (ton*UKM) ${ }^{-1}$ arasında biyogaz elde edilebilmektedir (Seyhan ve Badem, 2018; Salihoğlu ve ark., 2019, Yağlı ve Yıldız, 2019). Hayvan türüne bağlı oluşan 1 ton toplam yaş gübre miktarından BBH için $33 \mathrm{~m}^{3}$ ton $^{-1}$, KBH için $58 \mathrm{~m}^{3}$ ton $^{-1}$ ve $\mathrm{KH}$ için $78 \mathrm{~m}^{3}$ ton $^{-1}$ biyogaz elde edilebilmektedir (Altıkat ve Çelik, 2012; Kaya ve Öztürk, 2012; Çağlayan ve Koçer, 2014; Ilgar, 2016; Baran ve ark., 2017; Doruk ve Bozdeveci, 2017; Şenol ve ark., 2017; Bayrak Işık ve Polat, 2018; Bulut ve Canbaz, 2019; Görgülü, 2019; Kocabey, 2019; Yetiş ve ark., 2019; Ay ve Kaya, 2020). Bu çalışmada biyogaz potansiyelinin hesaplanması için yaş gübre kabulündeki katsayılar kullanılmıştır. Yıllık toplam yaş gübre potansiyeli (TYGP);

$T_{Y G P}=T_{K Y G M} * N_{C H} * 365 / 1000$

eşitliği ile hesaplanmaktadır. Bu eşitlikte $\mathrm{N}_{\mathrm{CH}}$ hayvan sayısını ifade etmektedir. Yıllık biyogaz miktarı ( T Biyogaz ;

$T_{\text {Biyogaz }}=T_{Y G M} * M_{B}$

şeklinde hesaplanmaktadır. Burada $\mathrm{T}_{\text {Biyogaz }}$ ylllık oluşan biyogaz miktarını $\left(\mathrm{m}^{3} \mathrm{y}^{-1}{ }^{-1}\right), \mathrm{M}_{\mathrm{B}}$ hayvan türüne bağlı 1 ton yaş gübreden elde edilen biyogaz miktarını göstermektedir. Bu değer BBH için $33 \mathrm{~m}^{3}$ ton $^{-1}, \mathrm{KBH}$ için $58 \mathrm{~m}^{3}$ ton $^{-1}$ ve $\mathrm{KH}$ için $78 \mathrm{~m}^{3}$ ton $^{-1}$ alınmıştır. Biyogaz \%50- 70 arasında metan gazı içermektedir. Biyogazdan üretilebilecek enerji miktarı $\left(\mathrm{E}_{1 \mathrm{s1}}\right)$;

$E_{l s l}=T_{\text {Biyogaz }} * E_{B}$

şeklinde hesaplanmaktadır. Burada $\mathrm{E}_{1 \mathrm{~s}}$ yıllık oluşan biyogaz miktarından elde edilecek enerjinin 1sıl değerini ( $\left.\mathrm{MJ} \mathrm{yll}^{-1}\right)$ ve $\mathrm{E}_{\mathrm{B}}$ biyogazın 1sıl değerini $\left(\mathrm{MJ} \mathrm{m}^{-3}\right)$ ifade etmektedir. Oluşan biyogazın içeriğindeki metan oranına göre 1sıl değeri 20-27 $\mathrm{MJ} \mathrm{m}^{-3}$ arasında değişiklik göstermektedir (Eryaşar ve Koçar 2009; Bond ve Templeton, 2011; Kaya ve Öztürk, 2012; Ayhan, 2015). Bu sebepten dolay1 $1 \mathrm{~m}^{3}$ biyogazın 1sıl değeri $23.5 \mathrm{MJ} \mathrm{m}^{-3}$ olarak kabul edilmiştir. Biyogazın 23.5 MJ 1sıl değerinin elektrik enerjisi eşdeğeri $6.53 \mathrm{kWh}$ değerindedir $(1 \mathrm{kWh}=3.6 \mathrm{MJ})$. Biyogazdan elektrik enerjisi üretebilmek için kojenerasyon sisteminde yakılarak mekanik enerjiye dönüştürülmektedir. Kojenerasyon sisteminin elektriksel verimleri \%35-40 aralığında değişmektedir. Bu değer \%40 alınmış ve bu verimle çalışan 
kojenerasyon sistemi için $1 \mathrm{~m}^{3}$ biyogazın elektriksel eşdeğeri $2.61 \mathrm{kWh}$ olarak kabul edilmiştir. Toz kömürün yakılmasıyla $1 \mathrm{kWh}$ elektrik üretimi için ortalama sera gazı emisyonu $710 \mathrm{gCO}_{2}$ olurken, biyogazın yakılması için bu değer ortalama $26 \mathrm{gCO}_{2}$ 'dir (Melikoglu, 2013). Bu sayede hayvansal atıklardan biyogaz elde edilmesi ile yılda ne kadar $\mathrm{CO}_{2}$ salınımının engellenebileceğini hesaplamak için iki değer arasındaki fark alınarak $684 \mathrm{~g} \mathrm{kWh}^{-1}$ katsayısı kullanılarak hesaplanmıştır. Biyogaz potansiyelinin hesaplanmasında kullanılacak olan kabuller Çizelge 2'de özetlenmiştir.

Çizelge 2. Hayvan cinslerine göre kullanılan kabuller

\begin{tabular}{|c|c|c|c|}
\hline Kullanılan Kabuller & ВBH & КВH & KH \\
\hline Toplam yaş gübre miktarı- $\mathrm{T}_{\mathrm{YGM}^{-}}\left(\mathrm{kg}\right.$ gün.hayvan $\left.{ }^{-1}\right)$ & 27 & 2.48 & 0.26 \\
\hline Kullanılabilirlik- $\mathrm{Y}_{\mathrm{KG}-}(\%)$ & 65 & 13 & 99 \\
\hline Yaş gübreden elde edilen biyogaz oran1- $\mathrm{M}_{\mathrm{B}^{-}}\left(\mathrm{m}^{3}\right.$ ton $\left.^{-1}\right)$ & 33 & 58 & 78 \\
\hline Enerji isıl değeri $-\mathrm{E}_{1 \mathrm{s1}}{ }^{-}\left(\mathrm{MJ} \mathrm{m}^{-3}\right)$ & 23.5 & 23.5 & 23.5 \\
\hline Elektrik enerji değeri - $\left(\mathrm{kWh} \mathrm{y}_{1} \mathrm{l}^{-1}\right)$ & 2.63 & 2.63 & 2.63 \\
\hline Engellenen $\mathrm{CO}_{2}$ salımı değeri $\left(\mathrm{g} \mathrm{kWh}^{-1}\right)$ & 684 & 684 & 684 \\
\hline
\end{tabular}

\section{BULGULAR VE TARTIŞMA}

Iğdır iline ait hayvansal atıklardan kaynaklanan biyogaz potansiyelinin hesaplanabilmesi için il genelindeki hayvan sayıları ve hayvanlardan toplanabilecek toplam yaş atık miktarı hesaplanmıştır. Daha sonra biyogaz için kullanılabilir yaş gübre miktarları belirlenmiştir. Ardından biyogaz potansiyeli hesaplanarak gazın isıl ve elektriksel eşdeğerliği oluşturulmuştur. Ayrıca yenilenebilir enerji kaynaklarından biri olan biyogaz enerjisinin kullanılması ile elde edilecek elektrik enerjisinden $\mathrm{CO}_{2}$ salınımını ne kadar azaltacağı hesaplanmıştır. Belirlenen değerlere göre Iğdır ili 2020 yılı toplam canlı hayvan sayısından yola çıkarak ve belirtilen kabullerin yapılmasıyla gübre miktarı, elde edilecek biyogaz miktarı, enerji potansiyeli ve engellenecek $\mathrm{CO}_{2}$ emisyon salınımı belirlenmiştir.

Çalışma kapsamında öncelikle 2020 yılı için Iğdır ilinde TÜİK verilerine göre, Büyükbaş hayvan (BBH) olarak sığırlar (yerli-kültür-melez), küçükbaş hayvan $(\mathrm{KBH})$ olarak koyun ve keçi, kümes hayvanı $(\mathrm{KH})$ olarak da yumurta tavuğu, hindi, kaz, ördek ve beç tavuğu sayıları referans alınmış ve canlı hayvan sayıları verilmiştir (Çizelge 3).

Çizelge 3. 2020 yılına ait Iğdır ili ve ilçelerindeki canlı hayvan sayıları

\begin{tabular}{|c|c|c|c|c|}
\hline \multirow{2}{*}{ İlçe Adı } & \multicolumn{3}{|c|}{ Hayvan Sayısı } & \multirow{2}{*}{ Toplam } \\
\hline & BBH & KBH & KH & \\
\hline Merkez & 69966 & 742193 & 185250 & 997409 \\
\hline Aralık & 28268 & 225273 & 20380 & 273921 \\
\hline Karakoyunlu & 23102 & 134977 & 11283 & 169362 \\
\hline Tuzluca & 36090 & 176760 & 48260 & 261110 \\
\hline Toplam & 157426 & 1279203 & 265173 & 1701802 \\
\hline
\end{tabular}

Çizelge 3'te görüldüğü gibi Iğdır ilinde, BBH varlığının en fazla olduğu ilçe \%44'lık oran ile Merkez ilçesidir. BBH varlığının en az olduğu ilçe ise \%15'lik oran ile Karakoyunlu ilçesidir. Bu ilde, $\mathrm{KBH}$ varlığının en fazla olduğu ilçe \%58'lik oran ile Merkez ilçesi olarak belirlenmiştir. KBH varlığının en az olduğu ilçe ise \%10'luk oran ile Karakoyunlu ilçesidir. Ayrıca bu ilde, KH varlığının en fazla olduğu ilçe \% 70'lik oran ile Merkez ilçesi olduğu tespit edilmiştir. KH varlığının en az olduğu ilçe ise \%4'lük oran ile Karakoyunlu ilçesidir. Iğdır ili ve ilçelerindeki hayvan sayıları incelendiğinde $\mathrm{KBH}$ yetiştiriciliğinin daha yüksek orana sahip olduğu görülmektedir.

İldeki canlı hayvan sayılarına göre toplam yaş gübre potansiyeli (Eşitlik 4) ve elde edilecek biyogaz miktarı (Eşitlik 5) tespit edilmiştir (Çizelge 4). 
Çizelge 4. Iğdır ili ve ilçelerine ait BBH, KBH ve KH atıklarından elde edilecek yaş gübre ve biyogaz potansiyeli

\begin{tabular}{|c|c|c|c|c|c|c|}
\hline İlçe Adı & $\begin{array}{c}\text { Hayvan } \\
\text { Cinsi }\end{array}$ & $\begin{array}{l}\text { Hayvan } \\
\text { Miktarı } \\
\text { (adet) }\end{array}$ & $\begin{array}{c}\text { Toplam Yaş Gübre } \\
\text { Potansiyeli - TYGP- } \\
\text { (ton yll }^{-1} \text { ) }\end{array}$ & Toplam & $\begin{array}{l}\text { Biyogaz Miktarı } \\
\left(\mathbf{m}^{3} \mathbf{y l l}^{-1}\right)\end{array}$ & Toplam \\
\hline \multirow{3}{*}{ Merkez } & $\mathrm{BBH}$ & 69966 & 448184.705 & & 14790095.249 & \\
\hline & $\mathrm{KBH}$ & 742193 & 87338.303 & 552927.431 & 5065621.601 & 21213261.824 \\
\hline & $\mathrm{KH}$ & 185250 & 17404.423 & & 1357544.975 & \\
\hline \multirow{3}{*}{ Aralık } & $\mathrm{BBH}$ & 28268 & 181077.741 & & 5975565.453 & \\
\hline & $\mathrm{KBH}$ & 225273 & 26509.226 & 209501.688 & 1537535.082 & 7662448.802 \\
\hline & KH & 20380 & 1914.721 & & 149348.268 & \\
\hline \multirow{3}{*}{ Karakoyunlu } & $\mathrm{BBH}$ & 23102 & 147985.637 & & 4883526.005 & \\
\hline & $\mathrm{KBH}$ & 134977 & 15883.553 & 164929.239 & 921246.100 & 5887455.937 \\
\hline & $\mathrm{KH}$ & 11283 & 1060.049 & & 82683.832 & \\
\hline \multirow{3}{*}{ Tuzluca } & $\mathrm{BBH}$ & 36090 & 231183.518 & & 7629056.078 & \\
\hline & $\mathrm{KBH}$ & 176760 & 20800.410 & 256518.003 & 1206423.766 & 9189137.714 \\
\hline & $\mathrm{KH}$ & 48260 & 4534.075 & & 353657.870 & \\
\hline Toplam & & 1701802 & & 1183876.360 & & 43952304.278 \\
\hline
\end{tabular}

Yıllık kullanılabilecek olan yaş gübre miktarı toplamı 1183876.360 ton ve bu miktarın \%85'i BBH kaynaklı olduğu hesaplanmıştır. Şekil 2'te Iğdır ili ilçelerine göre hayvansal kaynaklı biyogaz potansiyelinin en yüksek olan ilçe Merkez ilçesinde olduğu görülmektedir. Elde edilebilecek bu enerji potansiyelinin \%76's1 BBH'lardan, \%20'si KBH'lardan ve \%4'ü de KH'lardan olduğu belirlenmiştir.

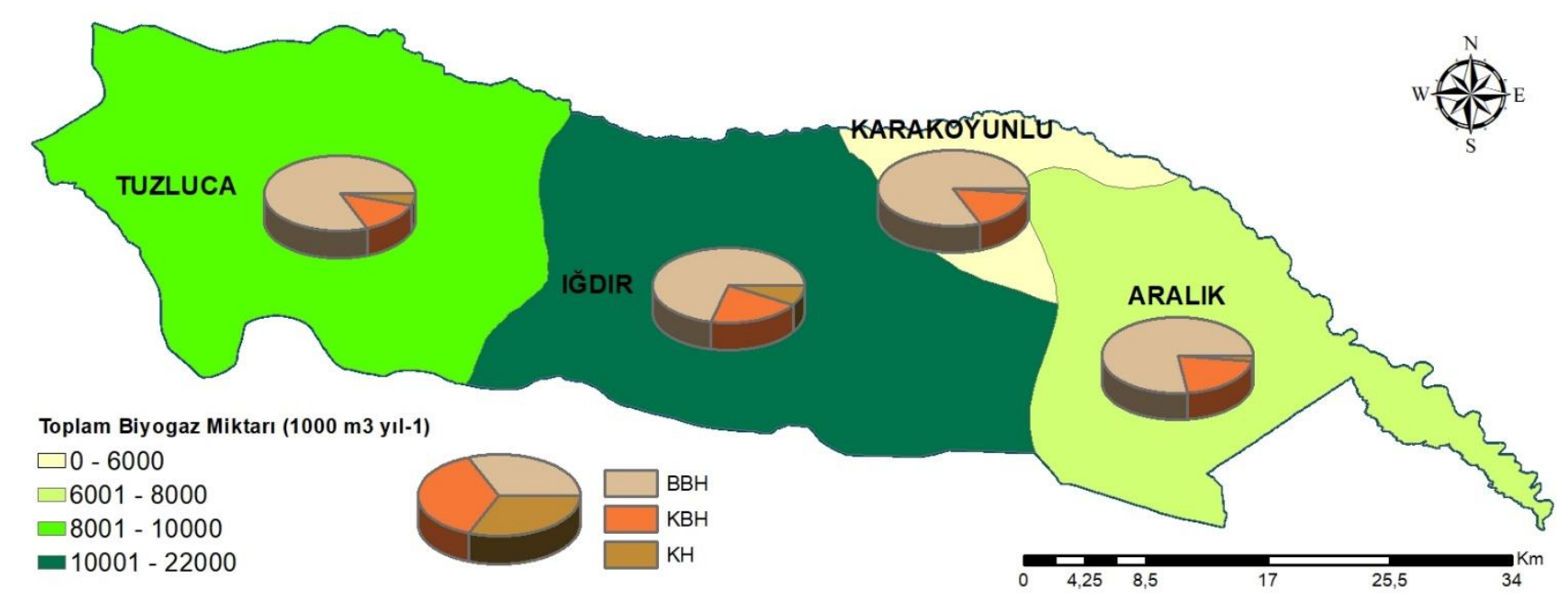

Şekil 2. Iğdır ili ilçelerine göre biyogaz enerji potansiyeli

Y1llık toplam biyogaz potansiyelinin hesaplanmasının ardından elde edilebilecek olan biyogazın 1sıl eşdeğerliği Eşitlik 6 ve elektriksel eşdeğerlikleri ise Çizelge 2'deki kabuller kullanılarak hesaplanmıştır. Iğdır ili genelinde biyogazdan üretilebilecek yıllık toplam elektrik üretim potansiyeli

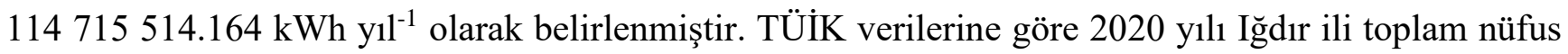
sayısı 201314 kişidir. Iğdır ili kişi başına toplam elektrik tüketim miktarı $1001 \mathrm{kWh} \mathrm{y}^{-1}{ }^{-1}$ dır. Bu değerler dikkate alındığında 2020 yılında tüketilen elektrik miktarı yaklaşık 2001515314 kWh'dır. Iğdır iline yapılacak biyogaz tesisi sayesinde ilin \%57'lik elektrik ihtiyacı karşılanabilecektir. 
Çizelge 5. Iğdır ili ve ilçelerine ait $\mathrm{BBH}, \mathrm{KBH}$ ve $\mathrm{KH}$ atıklarından elde edilecek enerji potansiyeli ve engellenen $\mathrm{CO}_{2}$ salınımı

\begin{tabular}{|c|c|c|c|c|c|c|c|}
\hline İlçe Adı & $\begin{array}{c}\text { Hayvan } \\
\text { Cinsi }\end{array}$ & $\begin{array}{c}\text { Enerji Isıl Değeri } \\
\left(\mathrm{MJ} \mathbf{y l l}^{-1}\right)\end{array}$ & Toplam & $\begin{array}{c}\text { Elektrik } \\
\text { Enerjisi Değeri } \\
\left(\mathbf{k W h} \mathbf{y l l}^{-1}\right)\end{array}$ & Toplam & $\begin{array}{c}\text { Engellenen } \\
\mathrm{CO}_{2} \text { Salımı } \\
\text { Değeri (ton } \\
\text { yll }^{-1} \text { ) }\end{array}$ & Toplam \\
\hline \multirow{3}{*}{ Merkez } & $\mathrm{BBH}$ & 347567238.340 & \multirow{3}{*}{498511652.867} & 38602148.599 & & 26403.869 & \multirow{3}{*}{37870.764} \\
\hline & $\mathrm{KBH}$ & 119042107.627 & & 13221272.379 & 55366613.361 & 9043.350 & \\
\hline & $\mathrm{KH}$ & 31902306.901 & & 3543192.383 & & 2423.543 & \\
\hline \multirow{3}{*}{ Aralık } & $\mathrm{BBH}$ & 140425788.146 & \multirow{3}{*}{180067546.857} & 15596225.832 & \multirow{3}{*}{19998991.374} & 10667.818 & \multirow{3}{*}{13679.310} \\
\hline & $\mathrm{KBH}$ & 36132074.422 & & 4012966.563 & & 2744.869 & \\
\hline & $\mathrm{KH}$ & 3509684.290 & & 389798.979 & & 266.622 & \\
\hline \multirow{3}{*}{ Karakoyunlu } & $\mathrm{BBH}$ & 114762861.106 & \multirow{3}{*}{138355214.522} & 12746002.872 & \multirow{3}{*}{15366259.996} & 8718.265 & \multirow{3}{*}{10510.522} \\
\hline & $\mathrm{KBH}$ & 21649283.355 & & 2404452.322 & & 1644.645 & \\
\hline & $\mathrm{KH}$ & 1943070.061 & & 215804.802 & & 147.610 & \\
\hline \multirow{3}{*}{ Tuzluca } & $\mathrm{BBH}$ & 179282817.821 & \multirow{3}{*}{215944736.276} & 19911836.362 & & 13619.696 & \multirow{3}{*}{16404.816} \\
\hline & $\mathrm{KBH}$ & 28350958.503 & & 3148766.029 & 23983649.433 & 2153.755 & \\
\hline & $\mathrm{KH}$ & 8310959.952 & & 923047.041 & & 631.364 & \\
\hline Toplam & & & 1032879150.522 & & 114715514.164 & & 78465.412 \\
\hline
\end{tabular}

Iğdır ilinde elektrik üretim enerji potansiyeli en düşük Karakoyunlu ilçesinde belirlenmişken en yüksek \%48 oranında Merkez ilçedir (Şekil 3).

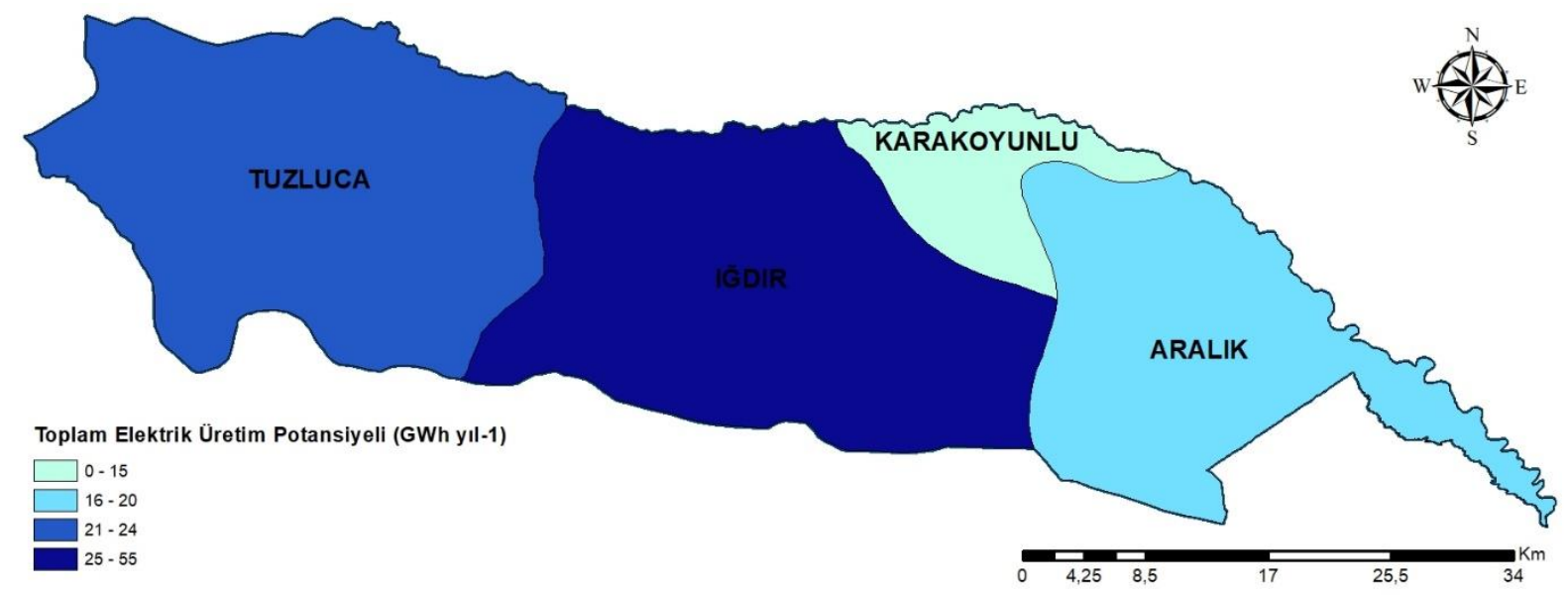

Şekil 3. Iğdır ili ilçelerine göre elektrik üretim potansiyeli

Literatürdeki çalışmalar incelendiğinde farklı sayıdaki hayvan varlıklarından yararlanarak teorik olarak biyogaz potansiyeli ve üretilebilecek enerji değerleri hesaplanabilmektedir. Bu çalışmalarda yıllık olarak; Çevik (2016) Çanakkale ilinin biyogaz potansiyelini $60793963 \mathrm{~m}^{3}$ ve elektrik enerji potansiyelini $156848426.42 \mathrm{kWh}$; Boyacı (2017) Kırşehir ilinin biyogaz potansiyelini $14855273 \mathrm{~m}^{3}$ ve elektrik enerji potansiyelini $69819781 \mathrm{kWh}$; Aksu (2019) Amasya ilinin biyogaz potansiyelini yaklaşı 35.9 milyon $\mathrm{m}^{3}$ ve elektrik enerji potansiyelini 90.474 milyon $\mathrm{kWh}$; Konuk (2019) Tokat ilinin biyogaz potansiyelini yaklaşı 49.2 milyon $\mathrm{m}^{3}$ ve elektrik enerji potansiyelini $124042 \mathrm{MWh}$; Gökdoğan (2019) Isparta ilinin biyogaz potansiyelini $22366468.22 \mathrm{~m}^{3}$ ve elektrik enerji potansiyelini 105122 $400.65 \mathrm{kWh}$; Bulut ve Canbaz (2019) Sivas ilinin biyogaz potansiyelini $52391785 \mathrm{~m}^{3}$ ve elektrik enerji potansiyelini 246.2 GWh; Akbay ve Kumbur (2020), Mersin ilinin biyogaz potansiyelini yaklaşık 60 milyon $\mathrm{m}^{3}$ ve elektrik enerji potansiyelini $280 \mathrm{GWh}$; Seyhan ve Badem (2021), Erzincan ilinin biyogaz potansiyelini $15511011 \mathrm{~m}^{3}$ ve elektrik enerji potansiyelini $38025864 \mathrm{kWh}$ olarak hesaplamışlardır. Literatürde verilen çalışma sonuçları ile bu çalışmada elde edilen sonuçlar karşılaştırıldığında sonuçların uyumlu olduğu görülmektedir.

İl genelinde tasarruf edilecek olan $1 \mathrm{kWh}$ elektriğe karşılık olarak $684 \mathrm{gCO}_{2}$ salınımının azaltılabileceği düşünüldüğünde hayvansal atıklardan biyogaz elde edilmesi ile yılda 78465 ton $\mathrm{CO}_{2}$ 
salınımının engellenebileceği belirlenmiştir. Bu sayede küresel ısınma konusunda en önemli gazlardan biri olan $\mathrm{CO}_{2}$ salınımının engellenmesi için biyogazın önemli avantaja sahip olduğu görülmektedir. İlçelere göre engellenen $\mathrm{CO}_{2}$ emisyon miktarının dağılım haritası incelendiğinde en fazla $\mathrm{CO}_{2}$ emisyonunun engellenmesine katkı sağlayan ilçe \%48'lik oran ile Merkez ilçesi olduğu ve daha sonra sırasıyla Tuzluca ilçesi, Aralık ilçesi ve Karakoyunlu ilçeleri olduğu görülmektedir (Şekil 4).

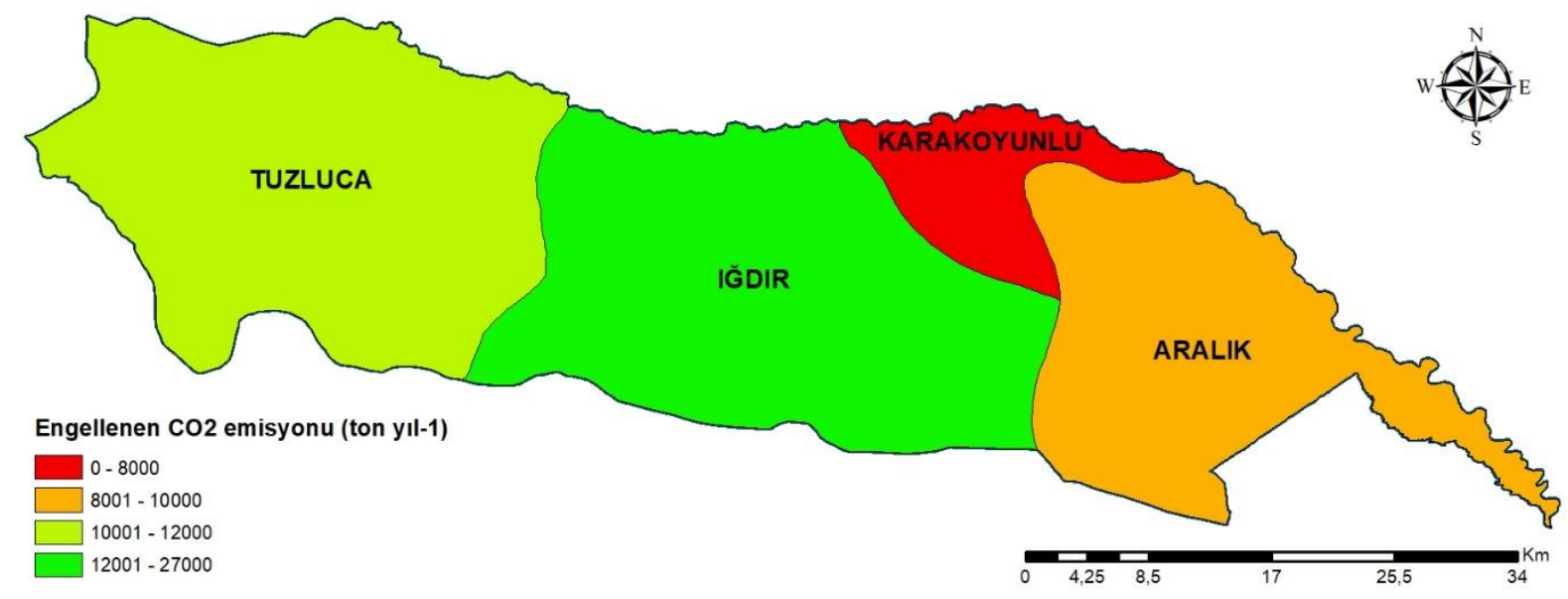

Şekil 4. Iğdır ili ilçelerine göre engellenen $\mathrm{CO}_{2}$ emisyonu oranları

Tırınk (2021) çalışmasında Iğdır il genelindeki yayılı kirletici yüklerinin tespiti amacıyla 2019 yılına ait büyükbaş hayvan, küçükbaş hayvan ve kümes hayvan sayıları sırasıyla 159 926; 1149668 ve 116916 adet olduğu ve bu hayvanların yıllık oluşturduğu yayılı kirletici yüklerinden toplam azot

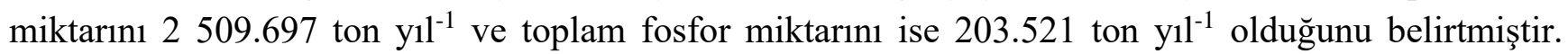
Çalışmamız 2019 yılı verileri ile karşılaştırıldığında, 2020 yılındaki hayvan sayılarında \%19'luk bir artış olduğu gözlemlenmiştir. Belirlenen artışa göre çevreye verilen kirlilik miktarlarında da artış olduğu söylenebilir. $\mathrm{Bu}$ nedenle kurulacak bir biyogaz tesisi sayesinde; kirlilik yüklerini engellemek hem küresel iklim değişikliğinin oluşmasında önemli bir gaz olan $\mathrm{CO}_{2}$ emisyonlarının biyogaz enerjisi kullanılarak fosil yakıtlara olan talebi azaltacak hem de Iğdır iline ekonomik katkı ve istihdam alanları sağlayacaktır.

\section{SONUÇ}

2020 yılı için Iğdır ilindeki canlı hayvan sayıları kullanılarak biyogaz potansiyeli araştırılmıştır. Iğdır ili 2020 yılı toplam 1701802 adet canlı hayvandan (\%75 BBH, \%16 KBH ve \%9 KH) oluşan hayvansal kaynaklı atık miktarı yıllık 1183876.360 ton kullanılabilir yaş gübre, $43952304.278 \mathrm{~m}^{3}$ biyogaz, 1032879150.522 MJ'luk enerji potansiyeli ve 114715514.164 kWh'lik elektrik enerji potansiyeli elde edilebileceği görülmüştür.

Dünya nüfusunun hızla artması ile enerjiye olan talepte de artış söz konusudur. Günümüzde doğal kaynak olan fosil yakıtların hızla tükendiği, küresel ısınma ve iklim değişikliğinin tehlikeli boyutlara ulaştığı, temiz enerji kaynaklarına olan ihtiyaç daha fazla önem kazanmıştır. Kyoto protokolü ve Paris iklim sözleşmesi ile $\mathrm{CO}_{2}, \mathrm{~N}_{2} \mathrm{O}, \mathrm{CH}_{4}, \mathrm{SF}_{6}$, $\mathrm{HFCs}$ ve PFCs gibi sera gazlarının azaltılması gerekliliği bir gerçektir. Ersoy (2017), sera gazlarından olan $\mathrm{CO}_{2}, \mathrm{CH}_{4}$ ve $\mathrm{N}_{2} \mathrm{O}$ gibi gazlar tarım ve hayvancılık faaliyetleri sonucu oluşumları söz konusu olduğunu ifade etmiştir. Biyogaz tesislerin yapılması ile gaz emisyonların yayılmasının önüne geçilerek, küresel ısınmanın ilerleyişinin azaltılmasına katkı sağlanacaktır.

$\mathrm{Bu}$ çalışmada hesaplanan biyogaz enerjisi; evlerde, yemek pişirme, aydınlanma ve ısınma, sanayide, elektrik ve isı enerjisi elde edilmesi, tarım da ise sera 1sitmada kullanılabilecektir. Ayrica il 
genelinde fosil yakıt kullanımı yerine yenilenebilir enerji kaynaklarından biri olan biyogaz enerjisinin kullanılması ile elde edilecek elektrik enerjisinden yıllık 78465 ton $\mathrm{CO}_{2}$ emisyon salınımı azaltılmasına bağlı karbon tasarrufu sağlanabilecektir. Biyogaz tesislerin kurulması ile hayvansal atıkların kontrollü bir şekilde bertarafları sonucunda çevreye vereceği zararlar (koku, yayılı kirlilik yükü, $\mathrm{CO}_{2}$ gibi) minimum düzeye indirilmiş ve enerji elde edilmesi sonucunda oluşan fermente edilmiş hayvansal gübrelerin organik gübre olarak da tarım arazilerinde değerlendirilmesine imkân sağlanmış olunacaktır. Ayrıca tarım ve hayvancılığın geliştirilmesine ve yaygınlaştırılmasına katkı sağlayacağı düşünülmektedir. Sonuç olarak bu tesislerin kurulması ile hem geleneksel enerji kaynaklarının sebep olduğu emisyonlar azaltılmış olacak hem de sürdürülebilir kalkınmaya destek olacaktır.

\section{Çıkar Çatışması}

Makalenin planlanması, yürütülmesi ve yazılması sırasında herhangi bir çıkar çatışması olmadığını beyan ederim.

\section{Yazar Katkısı}

Makalenin planlanmasının, yürütülmesinin ve yazılmasının makalenin tek yazarı olarak tarafımdan yapıldığını beyan ederim.

\section{KAYNAKLAR}

Akbay HEG, Kumbur H, 2020. Determination of Biogas Potential of Livestock Manure: A Case Study from Mersin Province. Academic Platform Journal of Engineering and Science, 8 (2): 295-303.

Aksu Y, 2019. Amasya ilindeki hayvansal atıkların biyogaz potansiyelinin belirlenmesi, Yüksek Lisans Tezi, Tokat Gaziosmanpaşa Üniversitesi Fen Bilimleri Enstitüsü, Tokat.

Aktaş T, Özer B, Soyak G, Ertürk MC, 2015. Tekirdağ İli’nde Hayvansal Atık Kaynaklı Biyogazdan Elektrik Üretim Potansiyelinin Belirlenmesi. Tarım Makinaları Bilimi Dergisi, 11 (1): 69-74.

Altıkat S, Çelik A, 2012. Iğdır İlinin Hayvansal Atık Kaynaklı Biyogaz Potansiyeli. Iğdır Üniversitesi Fen Bilimleri Enstitüsü Dergisi, 2 (1): 61-66.

Aras E, Tekay N, 2018. Çevre ve Şehircilik Bakanlığı Iğdır İli 2018 Yılı çevre durum raporu. T.C. Iğdır Valiliği Çevre ve Şehircilik İl Müdürlüğü, https://webdosya.csb.gov.tr/db/ced/icerikler/igd-r_cdr2018-20190930172121.pdf_(Erişim Tarihi 20.11.2021).

Ardıç İ, Taner F, 2014. Biokütleden Biyogaz Üretimi I. Anaerobik Arıtımın Temelleri, https://www.emo.org.tr/ekler/14101ec47c52b48_ek.pdf_(Erişim Tarihi 20.11. 2021).

Argun YA, Doğru S, Altıkat A, Bingül Z, 2016. Renewable Energy Sources of TRA2 Region (Iğdır,

Kars, Ardahan and Ağrı) for Sustainable Development. International Energy \& Engineering Conference (UEMK), 13-14 October, Gaziantep/ TURKEY.

Avcıoğlu AO, Çolak A, Türker U, 2013. Türkiye'nin Tavuk Atıklarından Biyogaz Potansiyeli. Tekirdağ Ziraat Fakültesi Dergisi, 10 (1): 21-28.

Ay ÖF, Kaya A, 2020. Kahramanmaraş İlinin Hayvansal Atık Kaynaklı Biyogaz Potansiyeli. Iğdır Üniversitesi Fen Bilimleri Enstitüsü Dergisi, 10 (4): 2822-2830.

Aybek A, Üçok S, İspir S, Bilgili ME, 2015. Türkiye'de Kullanılabilir Hayvansal Gübre ve Tahıl Sap Atıklarının Biyogaz ve Enerji Potansiyelinin Belirlenerek Sayısal Haritalarının Oluşturulması. Tekirdağ Ziraat Fakültesi Dergisi, 12 (3): 109-120.

Ayhan A, 2015. Biogas Production Potential from Animal Manure of Bursa Province. Uludağ Üniversitesi Ziraat Fakültesi Dergisi, 29 (2): 47-53.

Baran M, Lüle F, Gökdoğan O, 2017. Adıyaman İlinin Hayvansal Atıklardan Elde Edilebilecek Enerji Potansiyeli. Türk Tarım ve Doğa Bilimleri Dergisi, 4 (3): 245-249. 
Bayrak Işık EH, Polat F, 2018. The Biogas Potential That Can Be Obtained from The Animal Wastes of Tokat Province. Gaziosmanpaşa Bilimsel Araştırma Dergisi, 7 (3): 93-100.

Bond T, Templeton MR, 2011. History and Future of Domestic Biogas Plants in The Developing World. Energy For Sustainable Development, 15 (4): 347-354.

Boyacı S, 2017. Kırşehir İlinin Hayvansal Atık Kaynaklı Biyogaz Potansiyelinin Belirlenmesi. Türk Tarım ve Doğa Bilimleri Dergisi, 4 (4): 447-455.

Boyacı S, Akyüz A, Kükürtcü M, 2011. Büyükbaş Hayvan Barınaklarında Gübrenin Yarattığı Çevre Kirliliği ve Çözüm Olanakları. International Journal of Agricultural and Natural Sciences, 4 (1): 49-55.

Bulut AP, Canbaz GT, 2019. Hayvan Atıklarından Sivas İli Biyogaz Potansiyelinin Araştırılması. Karaelmas Science and Engineering Journal, 9 (1): 1-10.

Çağlayan GH, Koçer NN, 2014. Muş İlinde Hayvan Potansiyelinin Değerlendirilerek Biyogaz Üretiminin Araştırılması. Muş Alparslan Üniversitesi Fen Bilimleri Dergisi, 2 (1): 215-220.

Çevik A, 2016. Çanakkale İli’ndeki hayvansal atıkların biyogaz potansiyelinin değerlendirilmesi, Yüksek Lisans Tezi, Çanakkale Onsekiz Mart Üniversitesi Sosyal Bilimler Enstitüsü, Çanakkale. Dağtekin M, Aybek A, Bilgili ME, 2019. Adana ve Mersin'de Bulunan Etlik Piliç Kümeslerinde Oluşan Gübrenin Biyogaz ve Elektrik Üretim Potansiyelinin Belirlenmesi. Çukurova Üniversitesi Mühendislik-Mimarlık Fakültesi Dergisi, 34 (2): 9-22.

Doruk İ, Bozdeveci A, 2017. Denizli İlinin Kırsal Kesimlerinde Hayvansal Kaynaklı Atıklardan Biyogaz Potansiyelinin Belirlenmesi. Iğdır Üniversitesi Fen Bilimleri Enstitüsü Dergisi, 7 (3): 181-186.

Ersoy AE, 2017. Türkiye'nin Hayvansal Gübre Kaynaklı Sera Gazı Emisyonları Durumu ve Biyogaz

Enerjisi Potansiyeli, Hacettepe Üniversitesi Fen Bilimleri Enstitüsü, Yüksek Lisans Tezi (Basılmış).

Eryaşar A, Koçar G, 2009. Biyogazın Mevcut Isıtma Sistemlerinde Kullanılabilme Olanakları. Engineer

\& The Machinery Magazine, 50 (590); 10-16.

Gökdoğan O, 2019. Isparta İlinin Hayvansal Atıklarından Elde Edilebilecek Enerjinin Sera Isıtmasında Kullanımı. Akademia Doğa ve İnsan Bilimleri Dergisi, 5(1): 27-34.

Görgülü S, 2019. Burdur İlinin Hayvansal ve Bazı Tarımsal Atık Kaynaklı Biyogaz Potansiyelinin Belirlenmesi. El-Cezeri Journal of Science and Engineering, 6 (3): 543-557.

Ilgar R, 2016. Hayvan Varlığına Göre Çanakkale Biyogaz Potansiyelinin Tespitine Yönelik Bir Çalışma. Eastern Geographical Review, 21 (35): 89-106.

Karaman S, 2006. Hayvansal Üretimden Kaynaklanan Çevre Sorunları ve Çözüm Olanakları. Kahramanmaraş Sütçü İmam Üniversitesi Fen ve Mühendislik Dergisi, 9 (2): 133-139.

Kaya D, Öztürk HH, 2012. Biyogaz Teknolojisi: Üretim-Kullanım-Projeleme, Umuttepe Yayınları, İzmit/Kocaeli, 253.

Kocabey S, 2019. Balıkesir İli İçin Hayvansal Atık Kaynaklı Biyogaz Potansiyelinin Belirlenmesi. Avrupa Bilim ve Teknoloji Dergisi, (17): 234-243.

Koçer NN, Öner C, Sugözü İ, 2006. Türkiye'de Hayvancılık Potansiyeli ve Biyogaz Üretimi. Furat Üniversitesi Doğu Araştırmaları Dergisi 4 (2): 17-20.

Konuk M, 2019. Tokat ilindeki hayvansal atıkların biyogaz potansiyelinin belirlenmesi, Yüksek Lisans Tezi, Tokat Gaziosmanpaşa Üniversitesi Fen Bilimleri Enstitüsü, Tokat.

Melikoglu M, 2013. Vision 2023: Feasibility analysis of Turkey's renewable energy projection. Renewable Energy, 50:570-575.

Omer A, Fadalla Y, 2003. Biogas Energy Technology in Sudan. Renewable Energy, 28 (3): 499-507. 
Salihoğlu NK, Teksoy A, Altan K, 2019. Büyükbaş ve Küçükbaş Hayvan Atıklarından Biyogaz Üretim Potansiyelinin Belirlenmesi: Balıkesir İli Örneği. Ömer Halisdemir Üniversitesi Mühendislik Bilimleri Dergisi, 8 (1): 31-47.

Seyhan AK ve Badem A, 2021. Erzincan ili hayvansal atık kaynaklı biyogaz potansiyelinin değerlendirilmesine yönelik biyogaz tesisi senaryoları. Gümüşhane Üniversitesi Fen Bilimleri Enstitüsü Dergisi, 11(1): 245-256.

Seyhan AK, Badem A, 2018. Erzincan İlindeki Hayvansal Atıkların Biyogaz Potansiyelinin Araştırılması. Academic Platform Journal Of Engineering And Science, 6 (1): 25-35.

Sözer S, Kabaş Ö, Ünal İ, 2016. Biyogaz Üretimini Arttırmada Kullanılan Ön İşlemlere Bir Bakış. Tarım Makinaları Bilimi Dergisi, 12 (3): 171-176.

Şenol H, Elibol EA, Açıkel Ü, Şenol M, 2017. Biyogaz Üretimi İçin Ankara'nın Başlıca Organik Atık Kaynakları. Bitlis Eren Üniversitesi Fen Bilimleri Dergisi, 6 (2): 15-28.

Taşova M, 2019. Tokat-Erbaa İlçesindeki Hayvansal Kaynaklı Atıkların Enerji Potansiyel Değerlerinin Belirlenmesi. TÜBAV Bilim Dergisi, 12 (1): 14-19.

Taşova M, Yazarel S, 2019. Yozgat İli Hayvansal Kaynaklı Atıkların Biyogaz ve Enerji Potansiyellerinin Belirlenmesi. International Journal of Life Sciences And Biotechnology, 2 (1): 16-24.

Teker GN, Yılmaz A, 2018. Dokuz Eylül Üniversitesi Tinaztepe Kampüsü İnşaat-Çevre Mühendisliği Bölümleri-İşletme Fakültesi Binaları Enerji Etüt Raporu. Setaş Enerji San. Tic. Ltd. Şti., http://www.iklimin.org/wp-content/uploads/2018/01/4-Seta\%C5\%9F-Enerji-

Verimlili\%C4\%9Fi-Et\%C3\%BCd\%C3\%BC-Raporu.pdf_(Erişim Tarihi 20.11.2021).

Tırınk S, 2021. Iğdır İli ve İlçelerindeki Hayvansal Atıkların Çevresel Etkileri ve Yayılı Kirletici Yükü Hesab1. Black Sea Journal of Engineering and Science, 4 (2): 43-50.

TÜİK, 2020. Türkiye İstatistik kurumu (TÜİK) veri tabanı, https://tuikweb.tuik.gov.tr/ (Erişim Tarihi 20.11.2021).

Yağlı H, Yıldız K, 2019. Hayvan Gübresinden Biyogaz Üretim Potansiyelinin Belirlenmesi: Adana İli Örnek Hesaplama. Çukurova Üniversitesi Mühendislik-Mimarlık Fakültesi Dergisi, 34 (3): 35-48.

Yetiş AD, Gazigil L, Yetiş R, Çelikezen B, 2019. Hayvansal Atık Kaynaklı Biyogaz Potansiyeli: Bitlis Örneği. Akademik Platform Mühendislik ve Fen Bilimleri Dergisi, 7 (1): 74-78. 